\title{
DIFFERENCE IN THE DISTRIBUTION OF SELECTED BLOOD VARIABLES AMONG ATHLETES DURING A COMPETITION PERIOD
}

\author{
Sam Mugandani, Trayana Djarova-Daniels
}

\begin{abstract}
Summary
Exercise is known to cause considerable changes in leucocyte counts and functions. The aim of the present study was to investigate the effect of exercise on leukocyte counts in athletes of different sporting codes during the competition time of the season.

Forty two $(n=42)$ active university athletes voluntarily participated in the study, rugby players $(n=9)$, male soccer players $(n=17)$, female soccer players $(n=9)$ and female netball players $(n=7)$. Blood samples were collected and blood analysis for whole blood count was done in Lancet laboratory, Richards Bay, RSA. Data were analyzed using unpaired $t$-test for treatment independent samples.

It is noteworthy to point out the higher levels of leucocytes in the netball players than female soccer players $(6.8 \pm 1.24$ $X 10^{9} / \mathrm{L}$ and $6.11 \pm 1.28 \times 10^{9} / \mathrm{L}$ respectively). The lymphocyte levels were also higher in the netball players than female soccer players $\left(2.60 \pm 0.58 \times 10^{9} / \mathrm{L}\right.$ and $2.16 \pm 0.49 \times 10^{9} / \mathrm{L}$ respectively). There were also higher levels of leucocytes in the male soccer players compared to male rugby players $\left(6.26 \pm 1.97 \times 10^{9} / \mathrm{L}\right.$ and $5.46 \pm 0.99 \mathrm{X} 10^{9} / \mathrm{L}$ respectively). The lymphocyte levels were higher in the soccer players than the rugby players $\left(2.17 \pm 0.36 \mathrm{X10^{9 }} / \mathrm{L}\right.$ and $1.85 \pm 0.32 \mathrm{X} 10^{9} / \mathrm{L}$ respectively), but the differences were however not significant at $p<0.05$.

The changes in leucocytes could be a result of among other things the removal of dead cells related to exercise stress and trauma. It was expected, considering the levels of physical contact that the leucocyte counts and the lymphocytes in particular were going to be higher among female soccer players and male rugby players compared to netball players and soccer male players respectively. The athletes' results for the measured blood parameters were within the health norms. These findings could be related to the less intensive training protocols and lower levels of physical contact and stress in players of students teams compared to professional players.
\end{abstract}

Key words: leucocytes, lymphocytes, exercise stress, athletes.

Introduction Training of athletes is intended to ensure that athletes reach their peak condition and produce performance which ensures that they succeed during competition. There is a complex relationship between training and competition. There is need therefore to have processes which can be used to monitor how athletes respond to training. There are a number of procedures which are used by coaches and sports scientists to monitor how athletes respond to both training during preparation for competition and during the competition period itself. A number of biochemical markers are being used to monitor fitness and fatigue of athletes (Coutts \& Cormack, 2014).Muscle damage has been detected through blood markers and enzymes such as creatine kinase (CK) (Clarkson et al., 2005; Yamin et al., 2007). Myoglobin, troponin, urea, uric acid and ammonia have also been used as biomarkers of muscle damage (Kirwan et al., 1990). The hormones cortisol from saliva has been used as a marker and has been shown to be elevated soon after competition (Elloumi et al., 2003; Haneish et al., 2007). Elloumi et al., 2003 have also reported the use of the hormone testosterone as an exercise marker. White blood cells and platelets increase following exercise hence are biomarkers of oxidative stress (Djarova et al., 2010), and may be useful to a clinician to better assess and evaluate the benefits of training and/ or supplementation programmes (Banfi et al., 2006). It is established that exercise of elevated intensity compromises the immune system leaving athletes susceptible to illness (Allgrove et al., 2012). Leucocytes and cytokines have been used as possible markers of compromised immune system due to exercise (Mackinnon 1997; Gleeson $\&$ Walsh 2012).

Exercise is known to cause considerable changes in leucocyte counts and functions. The aim of the present study was to investigate the effect of exercise on leukocyte counts in athletes of different sporting codes during the competition time of the season.

Methodology Forty two $(n=42)$ active university athletes voluntarily participated in the study, the participants' ages were $21.76 \pm 3.24$. They were all students recruited from the University of Zululand 
as follows: rugby players $(\mathrm{n}=9)$, male soccer players $(n=17)$, female soccer players $(n=9)$ and female netball players $(n=7)$. They had regular training sessions of two hours or more with a frequency of five to six times a week. They were also involved in club competitions of the UThungulu District in the Kwa-Zulu Natal province as well as inter- university games. As part of their obligation in the clubs and university games, they played competitive matches during the weekends. All participants participated in the study on a voluntary basis. The objectives of the study were explained to them and the possible risks of participating in the study were clearly elucidated, after which written consent was obtained from each one of the participants. A medical professional sought information on any diseases they might have had before, their present health status and any medication which they could have been taking. The following constituted the exclusion criteria; current infection, history of chronic disease use of antibiotics, herbal, antioxidant and steroids containing supplements. The study protocols were conducted in accordance with the Helsinki Declaration for the Ethical Treatment of Human Subjects and were evaluated and approved by the ethics committee of the Faculty of Science and Agriculture at the University of Zululand.

Blood samples were collected and blood analysis for whole blood count was done in Lancet laboratory, Richards Bay, RSA. Data were analyzed using unpaired $t$-test for treatment of independent samples.

Results It is noteworthy to point out the higher levels of leucocytes in the netball players than female soccer players $\left(6.8 \pm 1.24 \times 10^{9} / \mathrm{L}\right.$ and $6.11 \pm$ $1.28 \times 10^{9} / \mathrm{L}$ respectively). The lymphocyte levels were also higher in the netball players than female soccer players $\left(2.60 \pm 0.58 \times 10^{9} / \mathrm{L}\right.$ and $2.16 \pm 0.49$ $\mathrm{X} 10^{9} / \mathrm{L}$ respectively). There were also higher levels of leucocytes in the male soccer players compared to male rugby players $\left(6.26 \pm 1.97 \mathrm{X} 10^{9} / \mathrm{L}\right.$ and 5.46 $\pm 0.99 \mathrm{X} 10^{9} / \mathrm{L}$ respectively). The lymphocyte levels were higher in the soccer players than the rugby players $\left(2.17 \pm 0.36 \mathrm{X} 10^{9} / \mathrm{L}\right.$ and $1.85 \pm 0.32 \times 10^{9} / \mathrm{L}$ respectively), but the differences were however not significant at $\mathrm{p}<0.05$.

Discussion The changes in leucocytes could be a result of among other things the removal of dead cells related to exercise stress and trauma. It was expected, considering the levels of physical contact that the leucocyte counts and the lymphocytes in particular were going to be higher among female soccer players and male rugby players compared to netball players and soccer male players respectively. The relatively higher levels of leucocytes and lymphocytes in rugby and female soccer players reflect what has been obtained in other studies which show an increases of constituents of leucocytes such as the insulin-like growth factor 1 (IGF-1) which have a regulatory role in the immune response for muscle repair (Fragala et al., 2014). High competition physical exercise stress was seen to induce oxidative stress and activation of leucocytes in adolescents in fairly the same way as seen in individuals in our study who were also adolescents (Santos-Silvaa et al., 2001). Lymphocytes and their subsets have also been known to increase with exercise (Hong et al., 2004).

Conclusions The athletes' results for the measured blood parameters were within the health norms. These findings could be related to the less intensive training protocols and lower levels of physical contact and stress in players of students teams compared to professional players.

\section{Acknowledgements}

The authors would like to thank the University of Zululand for funding of the project.

\section{Reference}

Allgrove, J.E., Chapman, M., Christides, T. \& Smith, P.M, (2012), Immunoendocrine responses of male spinal cord injured athletes to 1-hour self-paced exercise: Pilot study. Journal of Rehabilitation Research Development. 49(6): pp. 925-34.

Banfi, G. Malavazos, A., Iorio, E., Dolci, A., Doneda, L. Verna, R. \& Corsi, M. M. (2006). Plasma oxidative stress biomarkers, nitric oxide and heat shock protein 70 in trained soccer players. European Journal of Applied Physiology, 96, pp. 483-486.

Clarkson PM, Hoffman EP, Zambraski E, Gordish-Dressman H, Kearns A, Hubal M, Harmon B, Devaney J.M. (2005). ACTN3 and MLCK genotype associations with exertional muscle damage. Journal of Applied Physiology: 99: pp. 564-56.

Coutts, A.J. \& Cormack, S. (2014), Monitoring the training response in Joyce, D \& Lewindon, D, (Eds.) High-performance training for sports, Human Kinetics, Champaign.

Djarova, T., Andreeva, L., Stefanova, D., Mateev, G., Tzvetkov, S., \& Bonov, P. (2010). Dark chocolate supplementation impact on blood oxidative biomarkers in track athletes submitted to maximal exercise tests. Proceedings of the $5^{\text {th }}$ International Congress "Sport, Stress Adaptation-Olympic Sport and Sport for All", Journal of Sport 
Science Special issue, 1, pp. 330-336.

Elloumi, M., Maso, F., Michaux, O., Robert, A. \& Lac, G. (2003), Behavior of saliva cortisol [C] testosterone $[\mathrm{T}]$ and $\mathrm{T} / \mathrm{C}$ ratio during a rugby match and during the post-competition recovery days. European Journal of Applied Physiology, 90(1-2): pp. 23-28.

Fragala, M.S., Jajtner, A.R., Townsend, J.R., Gonzalez, A.M., Wells, A.J., Oliveira, L.P., Hoffman, J.R., Stout, J.R. \& Fukuda, D.H.(2014), Leukocyte IGF-1 Receptor Expression during Muscle Recovery. Medicine and Science in Sport and Exercise, 47(1): pp. 92-99.

Gleeson, M. \& Walsh, N.P. (2012), The BASES Expert Statement on Exercise, Immunity and Infection, Journal of Sports Sciences, 30(3): pp. 321-324.

Haneish, Fry, Moore, Schilling, Li \& Fry, (2007), Cortisol and stress responses during a game and practice in female collegiate soccer players, Journal of Strength and Conditioning, 21(2): pp. 583-588.

Hong, H., Farag, N., Nelesen, R., Ziegler, M. \& Mills, P.J.(2004), Effects of regular exercise on lymphocyte subsets and CD62L after psychological vs. physical stress, Journal of Psychosomatic Research, 56 (3): pp. 363-368.
Kirwan, J.P., Costill, D.L., Houmard, J.B., Mitchel, J.B., Flynn, M.G. \& Fink, W.J.(1990), Changes in selected blood measures during repeated days of intense training and carbohydrate control, International Journal of Sports Medicine, 11: pp. 362-366.

Santos-Silvaa, A., Rebelo, M.I., Castro, E., M., B., Belo, L., Guerra, A., Rego, C. Quintanilhab, A. (2001) Leukocyte activation, erythrocyte damage, lipid profile and oxidative stress imposed by high competition physical exercise in adolescents Clinica Chimica Acta 306: pp. 119-126.

Yamin, C., Amir, O., Sagiv, M., Attias, E., Meckel, Y., Eynon, N., Amir, R.E., (2007), ACE ID genotype affects blood creatine kinase response to eccentric exercise. Journal of Applied Physiology, 103: pp. 2057-2061

Corresponding author: Sam C Mugandani, (MSc, MEd, BEd), CentreforBiokinetics, Recreation andSportScience, University of Venda, Private Bag X5050, Thohoyandou, 0950, South Africa; Mobile phone: +27726819044 ; Office: +27159628651 ; Fax: +27159624749 ; E-mail: sam. mugandani@univen.ac.za 